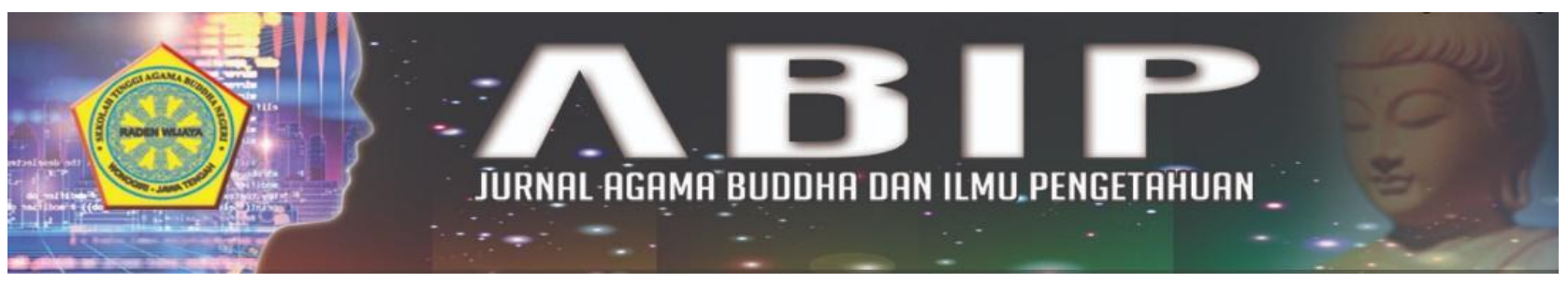

\title{
UPAYA MENINGKATKAN KECERDASAN EMOSIONAL SISWA SMB VIHARA VAJRA BODHI MANGGALA MENGGUNAKAN METODE DISCOVERY-INQUIRY LEARNING
}

\author{
Kartika Indah Sundari \\ Sekolah Tinggi Agama Buddha (STAB) Kertarajasa \\ kartikasundari424@gmail.com
}

\begin{abstract}
Abstrak
Penelitian ini bertujuan untuk mendeskripsikan peningkatan kecerdasan emosional melalui metode pembelajaran discovery-inquiry learning pada siswa Sekolah Minggu Buddha Vihara Vajra Bodhi Manggala Kudus. Penelitian ini merupakan jenis penelitian tindakan kelas yang terdiri dari 2 siklus dengan empat langkah pendekatan yaitu perencanaan, tindakan, observasi, dan refleksi. Teknik pengumpulan data menggunakan angket, observasi, evaluasi, dan dokumentasi. Hasil penelitian ini dapat dibuktikan dengan hasil evaluasi kecerdasan emosional siswa 649 atau 81,12\% pada siklus 1 meningkat menjadi 684 atau 85,5\% pada siklus 2. Berdasarkan pengamatan klasikal membuktikan peningkatan kecerdasan emosional siswa 15 atau 53,57\% pada pra-tindakan meningkat 59 atau $73,75 \%$ pada siklus 1 dan 76 atau $95 \%$ pada siklus 2 . Sedangkan berdasarkan pengamatan individual 552 atau $69 \%$ pada siklus 1 meningkat menjadi 778 atau 97,25 pada siklus 2 . Berdasarkan hasil peningkatan kecerdasan emosional siswa dapat disimpulkan bahwa metode pembelajaran discoveryinquiry learning dapat meningkatkan kecerdasan emosional siswa Sekolah Minggu Buddha Vihara Vajra Bodhi Manggala Kudus.
\end{abstract}

Kata Kunci: Kecerdasan emosional, metode pembelajaran dicovery-inquiry learning.

\begin{abstract}
This research aims to describe the increase in emotional intelligence through the discovery inquiry learning method to students Buddhist Vihara Vajra Bodhi Manggala Sunday School Kudus. This is a type of classroom action research, this research consists of 2 cycles with a four-step approach, namely planning, action, observation, and reflection. Data collection techniques using questionnaires, observation, evaluation, and documentation. The results can be proven by the evaluation of students' emotional intelligence 649 or $81.12 \%$ in cycle 1 increasing to 684 or $85.5 \%$ in cycle 2. 59 or $73.75 \%$ in cycle 1 and 76 or $95 \%$ in cycle 2. Meanwhile, based on individual observations 552 or $69 \%$ in cycle 1 increased to 778 or 97.25 in cycle 2. Based on the results of increasing students' emotional intelligence, it can be concluded that discovery inquiry learning method can improve the emotional intelligence of Vihara Vajra Bodhi Manggala Sunday School students in Kudus.
\end{abstract}

Keyword: Emotional intelligence, discovery-inquiry learning method 
Pendidikan adalah usaha sadar dan terencana untuk mewujudkan suasana belajar dan proses pembelajaran agar peserta didik secara aktif mengembangkan potensi dirinya untuk memiliki kekuatan spiritual keagamaan, pengendalian diri, kepribadian, kecerdasan, akhlak mulia, serta keterampilan yang diperlukan dirinya, masyarakat, bangsa dan negara (Irmawati, 2016:1). Pendidikan agama Buddha merupakan salah satu subyek pelajaran pada pertemuan sekolah minggu Buddhis, dimaksudkan untuk membentuk manusia utuh. Tujuan utama dari pendidikan agama Buddha adalah menanamkan nilai-nilai luhur ajaran Buddha. Pendidikan agama Buddha pada sekolah minggu sebagai usaha untuk memelihara dan mengembangkan Buddha Dhamma untuk membentuk karakter Buddhis yang sesuai ajaran Buddha. Kecerdasan emosional adalah bagian keterampilan sosial yang menawarkan suatu kecenderungan adanya kualitas-kualitas yang diperlukan anak didik dalam berinteraksi dengan lingkungan sekitar. Dengan pengaplikasian metode discovery-inquiry learning ini diharapkan dapat memberikan kesempatan kepada siswa Sekolah Minggu Buddha di Vihara Vajra Bodhi Manggala Kudus untuk berfikir leih kreatif, mandiri, kritis, serta memiliki sikap bijak berdasarkan nilai-nilai luhur ajaran Buddha.

\section{METODE}

\section{Pendekatan dan Jenis Penelitian}

Jenis penelitian yang digunakan dalam penelitian ini adalah penelitian tindakan kelas (PTK). Pendekatan yang digunakan adalah deskriptif kualitatif dan deskriptif kuantitatif. Penelitian yang dilakukan secara deskriptif kualitatif karena pengambilan data yang dilakukan secara alami dan data dilaporkan dalam bentuk tulisan atau kata-kata, sedangkan penelitian yang dilakukan secara deskriptif kuantitatif artinya data berupa angka-angka (nilai) atau pertanyaan-pertanyaan yang diangkakan (discore/dinilai) (Akbar, 2009:8).

\section{Kehadiran dan Peran Peneliti}

Kehadiran dan peran peneliti adalah sebagai instrumen penelitian dan pengumpulan data. Peneliti mempunyai tanggungjawab penuh sebagai pengajar, pengamat, pengumpul data, penganalisis data, pewawancara, pelaksana tindakan, dan pelaksana semua rancangan penelitian.

\section{Waktu dan Lokasi Penelitian}

Waktu penelitian dilakukan pada semester genap tahun ajaran 2021/2022 selama lima bulan terhitung dari pada bulan Maret sampai dengan bulan Juli. Lokasi penelitian ini akan dilaksanakan di Vihara Vajra Bodhi Manggala yang berada di Desa Kutuk RT.01/RW.02 Gang 29. Kecamatan Undaan Kabupaten Kudus, Provinsi Jawa Tengah.

\section{Subjek Penelitian}

Arikunto (2002:107) mengatakan bahwa subjek penelitian adalah sumber data dalam penelitian yang bisa berupa orang, tempat, maupun Symbol. Subjek penelitian ini adalah siswa Sekolah Minggu Buddha (SMB) Vihara Vajra Bodhi Manggala yang masih dalam tingkat Sekolah Dasar (SD) kelas IV, V, dan VI. Siswa yang akan diteliti adalah siswa Sekolah Minggu Buddha tingkat SD yang berjumlah 10 .

\section{Data dan Sumber Data}

Data yang dikumpulkan dalam penelitian ini adalah data mengenai kecerdasan emosional siwa dengan sumber data siswa Sekolah Minggu Buddha (SMB) Vihara Vajra Bodhi Manggala yang masih berada pada tingkat Sekolah Dasar (SD).

\section{Teknik Pengumpulan Data}

Teknik pengumpulan data dalam penelitian ini menggunakan beberapa teknik pengumpulan data yaitu observasi, angket, dan dokumentasi.

\section{Analisis Data, Evaluasi, dan Refleksi}

Menurut Sugiyono (2010:335) analisis data adalah proses mencari dan menyusun secara sistematis data yang diperoleh dari hasil wawancara, catatan lapangan dan dokumentasi, dengan cara mengorganisasikan data ke dalam kategori, menjabarkan ke unitunit, melakukan sintesa, menyusun ke dalam pola, memilih mana yang penting dan yang akan dipelajari, dan membuat kesimpulan sehingga mudah dipahami oleh diri sendiri dan orang lain. Evaluasi atau tes dilakukan untuk membentu penelitian dalam mendapatkan hasil peningkatan kecerdasan emosional diri melalui metode pembelajaran Discovery-Inquiry Learning pada siswa Sekolah Minggu Buddha (SMB) Vihara Vajra Bodhi Manggala. 
Sedangkan Refleksi adalah aktivitas pembelajaran berupa penilaian atau umpan balik peserta didik terhadap guru setelah mengikuti serangkaian proses pembelajaran dalam jangka waktu tertentu.

\section{Desain Penelitian}

Model pelaksanaan PTK ini menggunakan model guru sebagai peneliti dengan model siklus PTK yang dikembangkan oleh Kemmis dan Taggart 1990 (dalam Akbar 2010:30).

\section{Kriteria Keberhasilan}

Tingkat keberhasilan Penelitian Tindakan Kelas (PTK) ini ditandai dengan adanya perubahan kearah yang lebih baik dari kecerdasan emosional siswa dalam proses pembelajaran yang dilakukan.

\section{HASIL}

1. Penerapan Metode Pembelajaran Discovery-Inquiry Learning dalam Upaya Meningkatkan Kecerdasan Emosional Siswa Sekolah Minggu Buddha Vihara Vajra Bodhi Manggala Kudus

Pembelajaran dengan menggunakan metode discovery-inquiry learning merupakan upaya atau stategi yang tepat dalam meningkatkan kecerdasan emosional siswa. Seperti yang dikemukakan oleh Roestiyah (2008:20) dengan menggunakan discovery ialah suatu cara mengajar yang melibatkan siswa dalam proses kegiatan mental melalui tukar pendapat, dengan diskusi, membaca sendiri dan mencoba sendiri, agar siswa dapat belajar sendiri. Oleh karena itu dalam strategi ini siswa diharapkan berperan aktif sehingga memberikan pengaruh yang positif dan peluang yang sangat besar bagi siswa agar lebih mudah memahami dan mengingat bahan ajar. Berdasarkan proses pembelajaran pada tahap pra-tindakan, ke siklus 1, dan ke siklus 2 tidak terlepas dari adanya perbaikan strategi pembelajaran. Sehingga strategi-strategi inilah yang mampu merangsang siswa untuk meningkatkan potensi kecerdasan emosional yang dimiliki.

2. Peningkatan Kecerdasan Emosional Siswa Melalui Metode Pembelajaran Discovery-Inquiry Learning pada Siswa Sekolah Minggu Buddha Vihara Vajra Bodhi Manggala Kudus
Pada siklus 1 berdasarkan observasi individual mendapat jumlah skor 552 atau $69 \%$ dengan rata-rata 55,2. Ada 5 siswa yang mendapat skor diatas rata-rata dan 5 siswa mendapat skor dibawah rata-rata; berdasarkan observasi klasikal mendapat jumlah skor 59 atau $73,75 \%$ dengan rata-rata 2,95; berdasarkan hasil evaluasi percaya diri siswa mendapat jumlah skor 649 atau 81,12\% dengan rata- rata 64,9. Ada 5 siswa yang mendapat skor diatas rata-rata dan 5 siswa mendapat skor di bawah rata-rata. Oleh karena itu, perlunya perbaikan untuk meningkatkan potensi kecerdasan emosional siswa.

Pada pembelajaran siklus 2, terjadi peningkatan skor berdasarkan hasil observasi individual mendapatkan jumlah skor 778 atau $97,25 \%$ dengan rata-rata 77,8. Ada 6 siswa yang mendapat skor diatas rata-rata, dan ada 4 siswa mendapat skor dibawah rata-rata; berdasarkan hasil observasi klasikal mendapat jumlah skor 76 atau 95\% dengan rata-rata 3,8; berdasarkan hasil evaluasi kecerdasan emosional mendapat jumlah skor 684 atau $85,5 \%$ dengan rata-rata 68,4. Dengan 10 siswa yang semuanya diatas rat-rata.

\section{KESIMPULAN}

Penerapan metode pembelajaran discovery-inquiry learning dapat meningkatkan kecerdasan emosional siswa Sekolah Minggu Buddha Vihara Vajra Bodhi Manggala. Hal ini dibuktikan berdasarkan hasil penelitian, hasil pengamatan yang dilakukan, serta analisis data dan pembahasan yang telah diuraikan dalam bab sebelumnya.

\section{Daftar Pustaka}

Akbar, Sa'dun. 2009. Penelitian Tindakan Kelas Filosofi, Metodologi, Implementasi Edisi Revisi. Yogyakarta: Cipta Media.

Akbar Sa'dun. (2010). Penelitian tindakan kelas. Yogyakarta: Cipta Media.

Arikunto, S. 2002. Metodologi Penelitian Suatu Pendekatan Proposal. Jakarta: PT Rineka Cipta.

Goleman, Daniel. 2000. Emotional Intelligence, Kecerdasan Emosional Mengapa EI Lebih Penting daripada IQ. Jakarta: PT. Gramedia Pustaka Utama. 
Jurnal

Agama Buddha dan Ilmu Pengetahuan

Irmawati, Dkk. 2016. Hubungan Kecerdasan Emosional Terhadap Prestasi Belajar Mahasiswa Ditinjau Dari Jenis Kelamin pada Jurusan Pendidikan Matematika Uin Alauddin Makassar. Jurnal Lentera Pendidikan, Makassar: Fakultas Tarbiyah dan Keguruan Uin Alauddin Makassar.

NN. 2008. Undang-undang Sistem Pendidikan Nasional. Jakarta: Sinar Grafika.

Roestiyah. 2008. Strategi Belajar Mengajar. Jakarta: Rineka Cipta.

Sugiyono. 2010. Metode Penelitian Pendidikan Pendekatan Kuantitatif, Kualitatif, dan R\&D. Bandung: Alfabeta.

Sutman. et.al. 2008. The Science Quest Using Inquiry/Discovery to Enchance Student Learning. San Francisco: Jossey-Bass. 